\title{
Factors Influencing Mechanical Properties and Bruise Susceptibility of Apples and Pears
}

\author{
J. L. García; M. Ruiz-Altisent; P. Barreiro \\ Departamento de Ingenieria Rural, Universidad Politécnica de Madrid, 28040, Madrid, Spain
}

Fruit turgidity and firmness have been shown to influence impact bruise susceptibility in apples and pears. Analysis of impact response showed that stresses in the tissues were higher in turgid fruit, so they were more susceptible to bruising. Turgidity changes seemed to be the cause of the lower susceptibility of fruits to damage after storage.

The physical parameter "deformation at skin puncture" was shown to indicate fruit turgidity changes and was found to be related to bruise susceptibility. The influence of fruit turgidity was greater than that of firmness. Fruits picked early were less susceptible to bruising than those picked later.

\section{Introduction}

Bruise damage is a major cause of quality loss for fresh frait market apples. Most bruising occurs as a result of impacts. Several researchers have shown that bruising is linearly related to impact energy (Chen and Sun, 'Pang et al. ${ }^{2}$ ), but bruising varies among varieties, and the amount of bruising which occurs at a constant value of impact energy is variable.

Several factors have been found to influence bruise susceptibility, but frequently researchers have obtained conflicting results. Klein, ${ }^{3}$ and Johnson and Dover ${ }^{4}$ showed that bruising increased from early to late harvest time. However, Diener et al. ${ }^{5}$ reported that bruising decreased as apples matured.

With respect to storage, $\mathrm{Klein}^{3}$ concluded that bruise volume decreased with storage time. On the other hand, Brusewitz and Bartsch ${ }^{6}$ reported that the change in bruise volume per unit change in total impact energy increased with storage time,

Fruit turgidity and firmness seem to affect bruise susceptibility. Horsfield et al. ${ }^{7}$ noted that desiccating the fruit to reduce turgor decreased bruise damage. Siyami et $a .^{8}$ and Timm et al..$^{9}$ found significant negative correlations between Magness-Taylor firmness and bruise diameter.

Saltveit ${ }^{18}$ reported that bruise susceptibility increased with increasing fruit temperature; however, Schoorl and Holt ${ }^{11}$ reported the opposite effect.

The object of this work was to determine the effects of irrigation, humidity conditions, harvest date and storage on fruit firmness, skin properties and bruise susceptibility, and to study the relationships between fruit physical properties and bruise damage.

\section{Materials and methods}

"Blanquilla" pears and "Golden Supreme" and "Golden Delicious" apples, harvested in commercial orchards of Lérida (Spain), were used to determine the effect of harvest date, storage, irrigation and humidity conditions on bruising, according to the following scheme.

For "Blanquilla" pears, crossed factors were: three harvest dates (9 August, 16 August and 23 August 1993); fruits tested the day after harvest and fruits tested after 2 months in cold storage $\left(1^{\circ} \mathrm{C}, 85 \%\right.$ r.h.). A total of 480 pears were tested $(3 \times 2 \times 80)$, that is 80 pears at each combination of harvest date and storage time ( $1 \mathrm{~d}$ or 2 months). Magness-Taylor firmness ranged from 41 to $85 \mathrm{~N}$ at harvest and from 36 to $76 \mathrm{~N}$ after storage (firmness values were measured with an $8 \mathrm{~mm}$ diameter plunger).

For "Golden Supreme" and "Golden Delicious" apples, crossed factors were as follows.

1. Three irrigation treatments. Trees without irrigation (during 2 weeks before first harvest), trees normally irrigated with drips of $0.55 \mathrm{~cm}^{3} / \mathrm{s}$ and trees overirrigated $\left(1.1 \mathrm{~cm}^{3} / \mathrm{s}\right.$ drips, during the 2 weeks before first harvest). Trees were irrigated once per day.

2. Relative humidity (two treatments). Apples were tested after $16 \mathrm{~h}$ in $100 \%$ r.h. (inside plastic bags), and also after $16 \mathrm{~h}$ in $35-40 \%$ r.h. (with air ventilation), 
both at the same ambient temperature, ranging from 20 to $25^{\circ} \mathrm{C}$; subsequent tests were also carried out at these temperatures.

3. Three harvest dates (29 July, 5 August and 12 August 1993 for "Golden Supreme" and 6 September, 13 September and 20 September 1993 for "Golden Delicious").

4. Fruits tested, as described in (2) above, both $16 \mathrm{~h}$ after harvest, and also $16 \mathrm{~h}$ after 3 months in cold storage $\left(1^{\circ} \mathrm{C}, 85 \%\right.$ r.h. $)$.

A total of 1080 apples were tested $(3 \times 2 \times 6 \times 2 \times$ 15), 540 of each variety and 15 apples at each combination of test conditions. For "Golden Supreme", firmness ranged from 31 to $57 \mathrm{~N}$ at harvest and 28 to $55 \mathrm{~N}$ after storage; "Golden Delicious" firmness ranged from 24 to $43 \mathrm{~N}$ at harvest and 14 to $32 \mathrm{~N}$ after storage.

Additional experiments were carried out in different orchards, with the aim of obtaining data from a wide range of fruits. "Golden Delicious" apples $(n=440)$, harvested at six different harvest dates (31 August, 3, $10,14,17$ and 24 September 1992) were tested the day after harvest. Firmness ranged from 12 to $42 \mathrm{~N}$.

"Golden Delicious" apples $(n=280)$, from two different orchards, were tested after 5 months in cold storage $\left(1^{\circ} \mathrm{C}, 85 \%\right.$ r.h.). Firmness ranged from 8 to 25 N.

"Granny Smith" apples $(n=240)$, harvested at three different harvest dates $(8,15$ and 21 October 1992) were tested the day after harvest. Firmness ranged from 27 to $41 \mathrm{~N}$.

"Blanquilla" pears $(n=240)$, harvested at three different harvest dates (27 July, 3 and 10 August 1992) were tested the day after harvest. Firmness ranged from 50 to $89 \mathrm{~N}$.

"Conference" pears $(n=480)$, harvested in three different harvest dates over 2 years $(13,20$ and 27 August 1992; 19, 28 August and 2 September 1993) were tested the day after harvest. Firmness ranged from 43 to $77 \mathrm{~N}$.

"Conference" pears $(n=240)$, harvested at three different harvest dates $(19,28$ August and 2 September 1993) were tested after 2 months in cold storage $\left(1^{\circ} \mathrm{C}, 85 \%\right.$ r.h.). Firmness ranged from 36 to $78 \mathrm{~N}$.

"Jules Guyot" pears $(n=160)$, harvested at two different harvest dates (13 and 20 July 1993) were tested the day after harvest. Firmness ranged from 62 to $104 \mathrm{~N}$.

All fruits were selected at random in a controlled plot made up of a row of five to 20 trees. Tests applied to all these fruits were as follows.

1. Penetration test. This was performed using an Instron Universal Testing Machine with a standard Magness-Taylor $8 \mathrm{~mm}$ diameter plunger at
$20 \mathrm{~mm} / \mathrm{min}$, with the skin removed. The maximum force (Magness-Taylor firmness) was measured.

2. Skin puncture. This was performed using the same Instron Machine with a $0.5 \mathrm{~mm}$ diameter puncture rod at $20 \mathrm{~mm} / \mathrm{min}$. Both maximum force and deformation were measured.

3. Impact test. The impact tester used has been described previously by García et al. ${ }^{12}$. The test was conducted using an instrumented free falling mass $(50.8 \mathrm{~g})$ with a $20 \mathrm{~mm}$ diameter spherical head, dropped onto the fruit from a height of $8 \mathrm{~cm}$. Impact parameters (maximum force and deformation) were recorded and bruises produced were measured.

4. Bruise size measurement. Bruises were allowed to develop for over $2 \mathbf{h}$. A section was taken by cutting through the centre of the bruised region and maximum width and depth of the bruise were measured with a stereoscopic microscope. Bruise volume was taken as an indicator of bruise susceptibility. The volume of bruised tissue, $\mathrm{BV}$, was calculated using the equation of Chen and Sun:'

$$
B V=\frac{\pi h D^{2}}{6}
$$

in which $h$ and $D$ are the depth and width of bruise, respectively.

A final experiment was carried out with 120 "Golden Delicious" apples, harvested on 6 and 20 of September 1993 . Fruits were stored at $1^{\circ} \mathrm{C}$ and $85 \%$ r.h. in a cold chamber from the day after harvest until the beginning of the tests (15 November 1993), when they were removed from the chamber and kept at room conditions $\left(20^{\circ} \mathrm{C}\right.$ and from 35 to $40 \%$ r.h.). Samples were tested over $8 \mathrm{~d}$ ripening under these room conditions; in this period, initial and final weights were determined and penetration, skin puncture and impact tests were performed.

\section{Results and discussion}

\subsection{Effect of irrigation}

Irrigation schedules in the last weeks before harvest were shown to influence fruit firmness (Fig. I). Normally watered trees produced firmer fruit than non-irrigated trees, presumably since rate of fruit ripening was affected. However, no changes were detected in skin physical properties or bruise susceptibility with respect to irrigation schedules.

\subsection{Effect of air relative humidity}

Fruits under different air relative humidity conditions, during the hours preceding testing, showed 
Table 1.

Physical properties and bruise susceptibility of fruits tested after $16 \mathrm{~h}$ in different air relative humidities (low r.h.: from 35\% to $44 \%$; high r.h.: 100\%) for "Golden Supreme" and "Golden Delicious" apples, at harvest and after storage. * significant difference at the level of 0.05 ; ns non significant; Newman-Keuls test

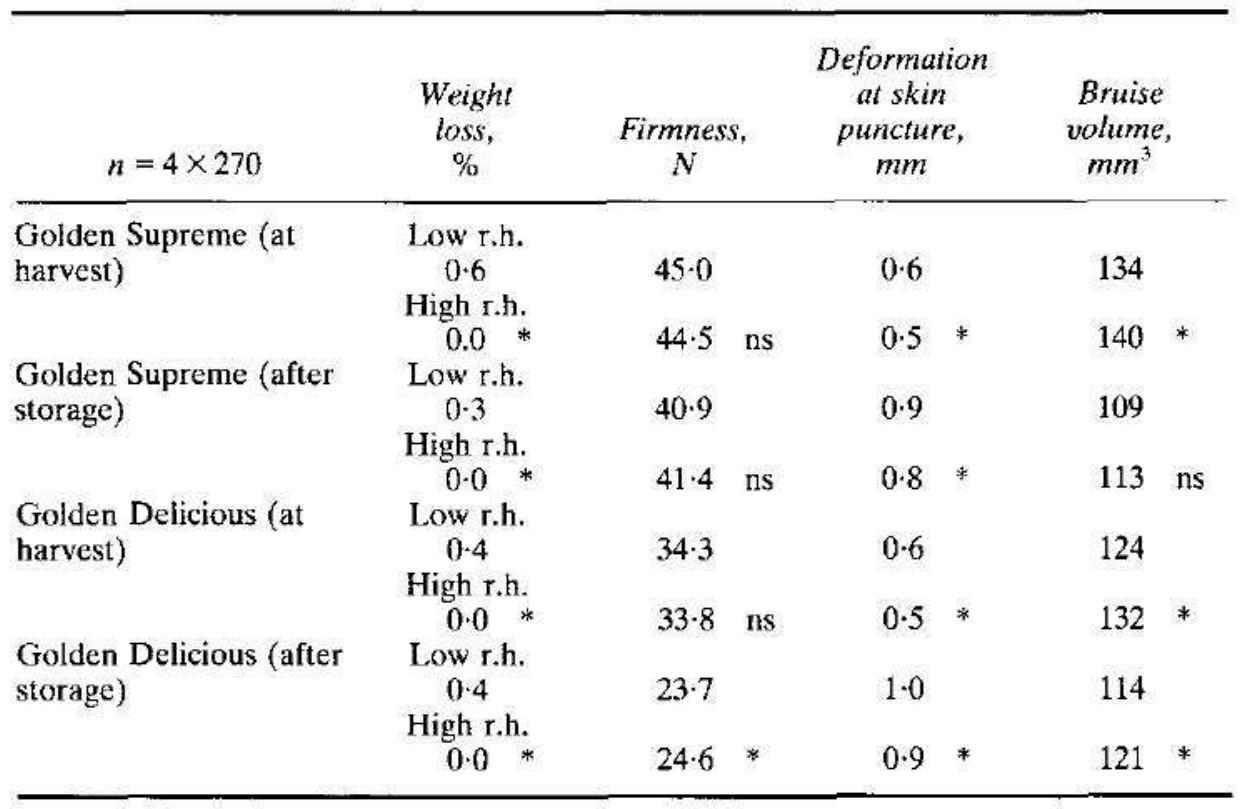

differences in their physical properties and bruise susceptibility (Table 1 ).

The maintenance of "Golden Supreme" and "Golden Delicious" apples in dry conditions (35-40\% r.h. and $20-25^{\circ} \mathrm{C}$, with ventilation) for $16 \mathrm{~h}$ led to weight losses smaller than $1 \%$, presumably in the external layers of the fruit, while fruits at the same temperature in wet air conditions ( $100 \%$ r.h.) did not suffer any weight loss. No changes in visible appearance were detected.

Deformation at skin puncture (DSP) was the parameter most related to weight loss. In all the cases, if
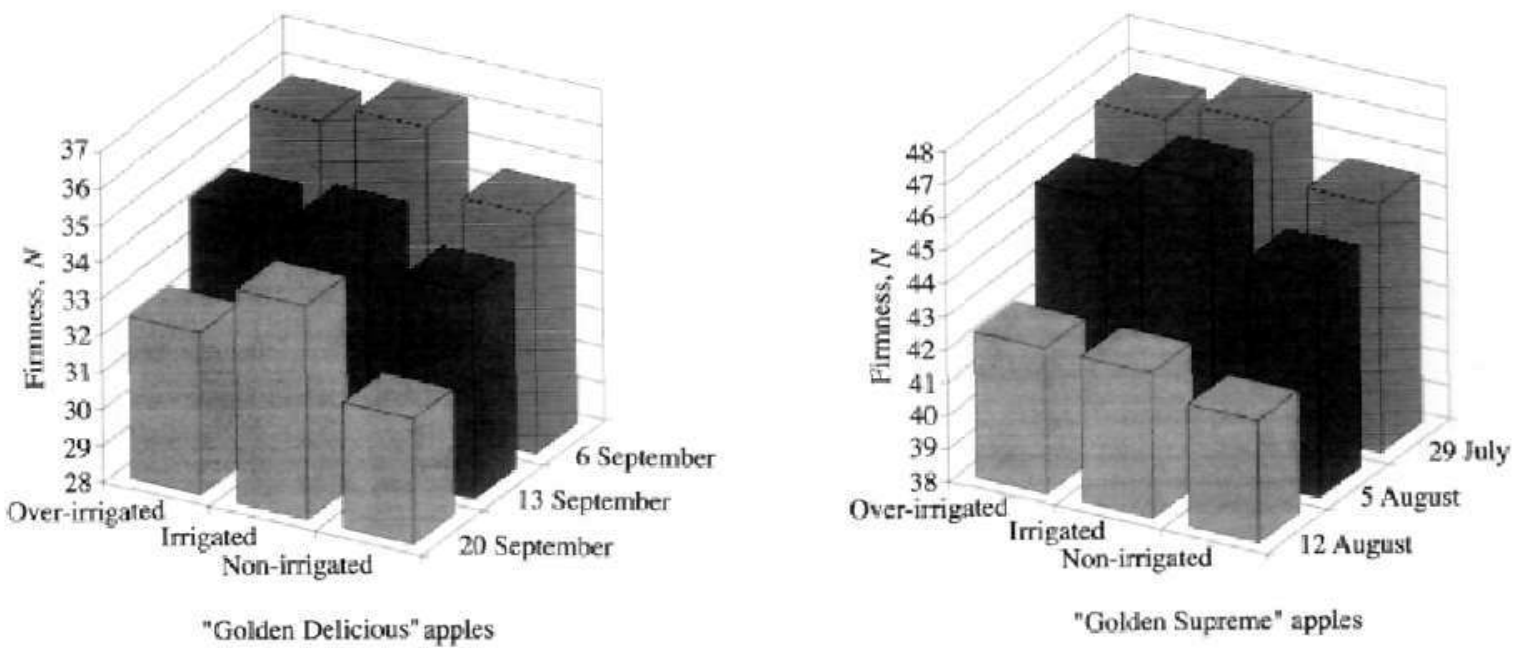

Fig. 1. Firmness values for different irrigation schedules ("Over-irrigated": watered with $1 \cdot 1 \mathrm{~cm}^{3} / \mathrm{s}$ drips, during 2 weeks before first harvest; "Irrigated": watered with $0.55 \mathrm{~cm}$ " $/ \mathrm{s}$ drips; "Non-irrigated"; without watering during two weeks before first harvest). Each column is the mean of 30 observations; least significant differences are 1.6 $N$ in "Golden Delicious" and $1.9 \mathrm{~N}$ in "Golden Supreme" at the level of $5 \%$ of significance 
the treatment produced differences in weight loss higher than $0.3 \%$, there were significant differences in the parameter DSP between the groups of fruits (Table 1). Assuming that weight loss is mainly due to water, and that turgidity decrease is related to water loss (Strasburger et al. ${ }^{13}$ ), deformation at skin puncture appearcd to be related to fruit turgidity.

Other experiments confirmed these results. Tests with "Golden Delicious" apples ripening for $8 \mathrm{~d}$ at room temperature also showed a relationship between weight loss and deformation at skin puncture ( $\mathrm{Fig} .2$ ). The values of deformation at skin puncture were in every case lower than $0.7 \mathrm{~mm}$ at harvest (turgid fruits) and higher than this value after storage (less turgid fruits) in "Golden Supreme" and "Golden Delicious" apples and also in "Blanquilla" and "Conference" pears; examples of DSP values at harvest and after storage are shown in Figs 3 and 4. More than 3200 fruits were tested and we can conclude that there is a relationship between deformation at skin puncture and fruit turgidity in these fruits.

There were significant differences in bruise susceptibility at different air humidities (Table 1, bruise volume values). Higher humidity caused larger bruise volumes.

Analysis indicated a relationship between deformation at skin puncture, DSP, and bruise susceptibility (Figs 3 and 4). Fruits with low values of DSP (turgid fruits) showed high values of bruise volume in samples of "Golden Supreme" and "Golden Delicious" apples and of "Blanquilla" pears. This relationship can be explained according to Hertz's contact theory. Turgid fruits exhibited different impact response compared to less turgid fruits. Figs 5 and 6 show that for a given

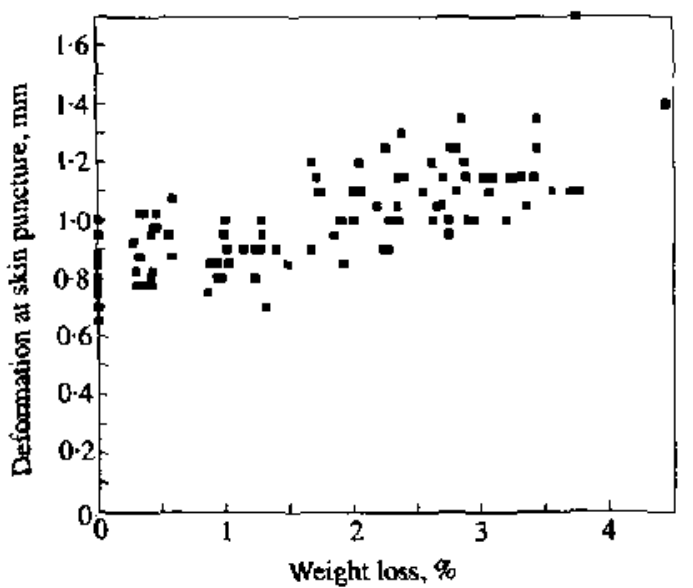

Fig. 2. Relationship between deformation at skin puncture, $D S P$, a physical parameter related to fruit turgidity, and weight loss, WL, in "Golden Delicious" apples, ripening for 8 days in room conditions $\left(20^{\circ} \mathrm{C}\right.$, from $35 \%$ to $40 \%$ r.h.). $n=120, r^{2}=0.59 ; D S P=0.81+0 \cdot 11 W L$

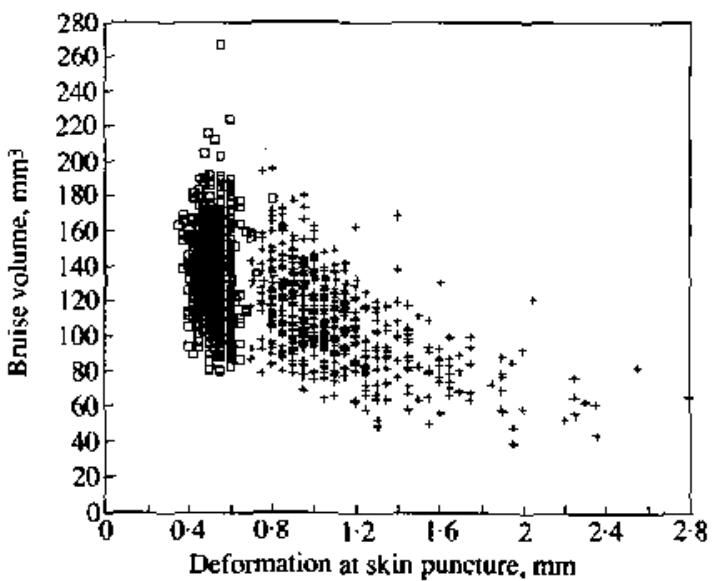

Fig. 3. Relationship between deformation at skin puncture, $D S P$, a pysical parameter related to fruit turgidity, and bruise volume, BV, in "Golden Delicious" apples, at harvest ( $\square$ ) and after storage $(+) . n=1260, r^{2}=0.34 ; B V=160 \cdot 5-47 \cdot 0$ $D S P$

impact energy, impact forces were higher and deformations lower in turgid fruits. Stresses in the tissue would therefore be higher, while Magness-Taylor firmness, related to tissue strength, did not change greatly between the two groups of fruit. This stress increase would be the reason for the increase in bruising.

The differences in turgidity can also explain why fruits at harvest were more susceptible to bruising than fruits after storage (Table 1, Figs 3 and 4 ), as observed previously by other researchers.

Magness-Taylor firmness was not affected by relative humidity, except in one case (Table 1, firmness values). This indicates that air humidity probably had no significant effect on fruit firmness or on the

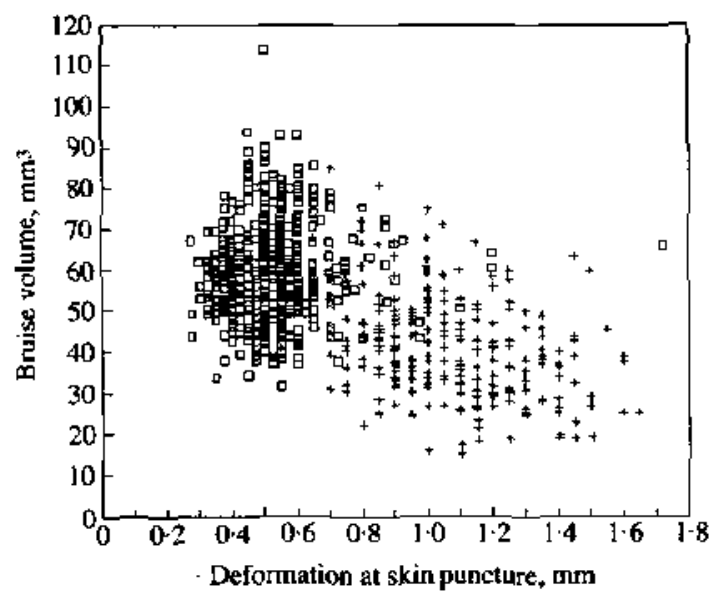

Fig. 4. Relationship between deformation at skin puncture, $D S P$, a pysical parameter related to fruit turgidity, and bruise volume, $B V$, in "Blanquilla" pears, at harvest ( $\square$ ) and after storage $(+), n=720, r^{2}=0.31 ; B V=73.5-27.8 D S P$ 


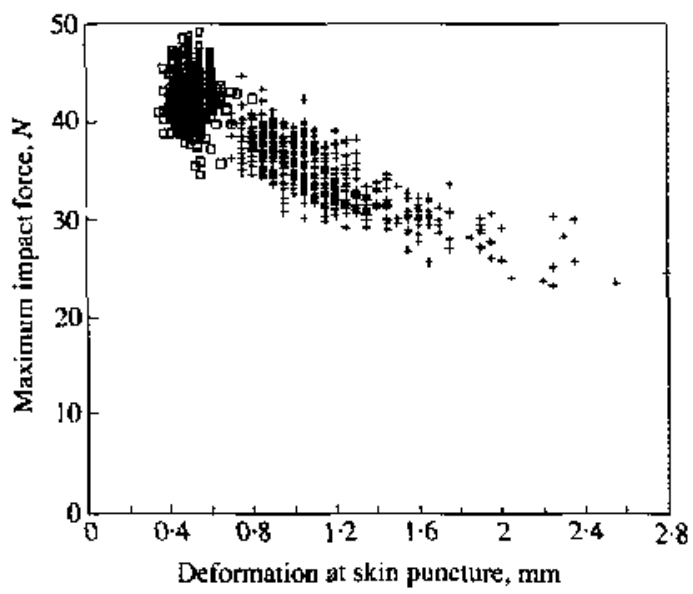

Fig. 5. Relationship between deformation at skin puncture, $D S P$, and maximum impact force, MIF, in "Golden Delicious" apples, at harvest (D) and after storage $(+)$. $n=1199, r^{2}=0.76 ; \quad M I F=48 \cdot 2-11.4$ DSP. All impacts with the same energy levels

strength of the tissues, as far as this strength is measured by Magness-Taylor firmness.

\subsection{Effect of harvest date and firmness}

With respect to harvest date, many researchers have reported that early picked fruits are less susceptible to bruising (Klein, ${ }^{3}$ Johnson and Dover ${ }^{4}$ ). The results presented here agree with those findings. However, this change in bruise susceptibility could not be explained by fruit turgidity; no changes were detected in the parameter DSP with respect to harvest dates in any of the varieties tested.

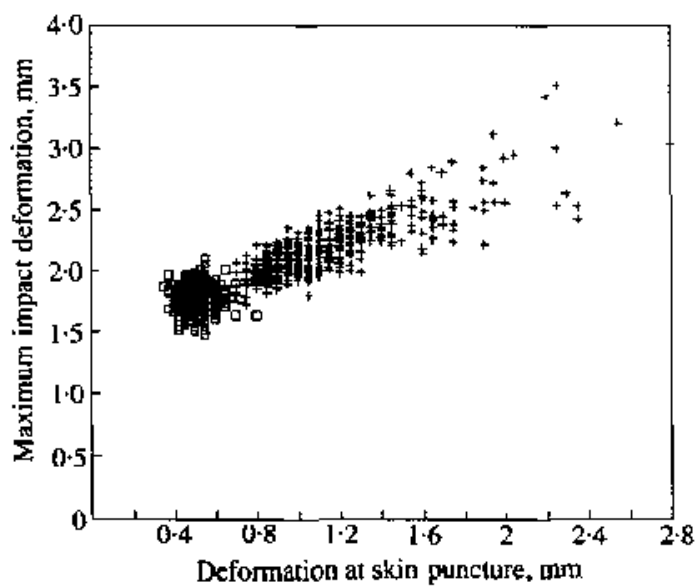

Fig. 6. Relationship between deformation at skin puncture, $D S P$, and maximum impact deformation, $M I D$, in "Golden Delicious" apples, at harvest ( $\square$ ) and after storage (+). $n=1199, r^{2}=0.80 ; \quad M I D=1.47+0.62$ DSP. All impacts with the same energy levels
Linear regression models, fitted with the statistical package STATITCF for "Golden Delicious" apples and for "Blanquilla" pears, were established using firmness and turgidity, for bruises produced with the same impact energy (Table 2).

For "Golden Delicious" apples $(n=1260$, individual fruits: bruise volume range, $50-200 \mathrm{~mm}^{3}$; firmness range, $8-43 \mathrm{~N}$; DSP range, $0.3-2.4 \mathrm{~mm}$ ) the regression model gave the equation:

$$
B V=193 \cdot 2-0.82 F-59 \cdot 7 D S P \quad r^{2}=0 \cdot 37
$$

where $B V$ is the bruise volume in $\mathrm{mm}^{3}, F$ is the Magness-Taylor firmness in $N$ and $D S P$ is the deformation at skin puncture in $\mathrm{mm}$.

For "Blanquilla" pears $(n=720$, individual fruits; bruise volume range, $20-90 \mathrm{~mm}^{3}$; firmness range, $36-89 \mathrm{~N}$; DSP range, $0 \cdot 3-1.6 \mathrm{~mm}$ ) the equation was found to be:

$$
B V=107 \cdot 6-0.51 F-32 \cdot 6 D S P \quad r^{2}=0.39
$$

These models have been analysed and show that the parameter DSP explains $34 \%$ of the total variation in "Golden Delicious" apples and $31 \%$ in "Blanquilla" pears. Adding the Magness-Taylor firmness, models can explain $37 \%$ and $39 \%$, respectively, of the total variation.

The results showed that Magness-Taylor firmness was related to bruise susceptibility, although to a lesser extent than turgidity. When testing fruit with similar turgidity (for instance, at harvest), firmer fruit were shown to be less susceptible to bruising (Table 3). Correlation coefficients between bruise volume and firmness were low, but significant and consistently negative in all tested varieties. The relationship between firmness and bruise susceptibility was closer in pears than in apples, since the ripening rate was faster in pears and the range of firmness values wider.

The parameters firmness and turgidity exhibited no relationship between each another and influenced bruising independently. According to the models, bruise susceptibility is affected by fruit turgidity and firmness changes during ripening; bruise damage would decrease with decreasing fruit turgidity, or would increase with decreasing firmness, depending on which is the main factor in the ripening process. This could be the cause of the conflicting results obtained by several researchers.

\section{Conclusions}

1. Irrigation schedules were shown to influence fruit firmness. Normally watered trees produced firmer fruit than non-irrigated trees. 
Table 2.

Parameters of the linear regression models established to explain bruise volume in terms of firmness, $F$, and deformation at skin puncture, DSP, for "Golden Delicious" apples and for "Blanquilla" pears. The statistical package used was STATITCF

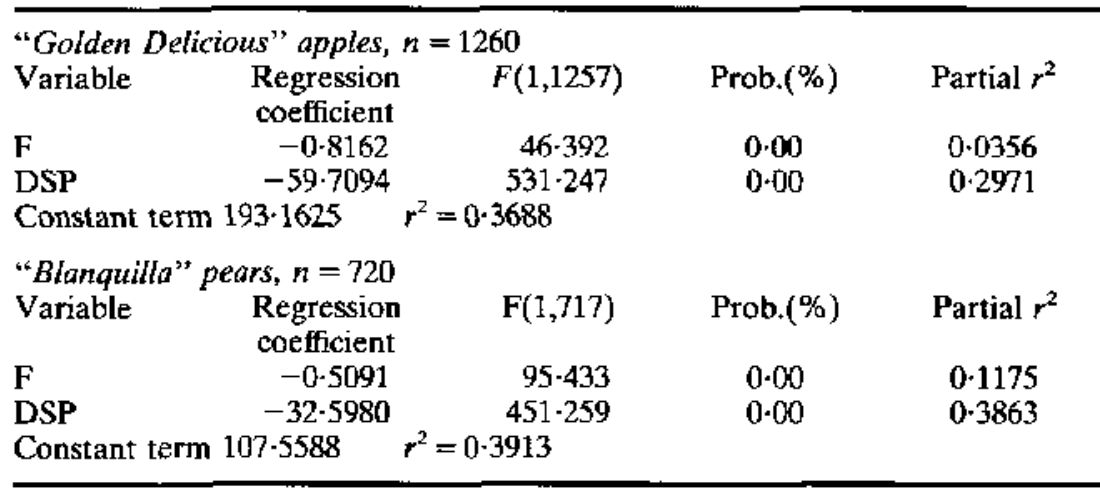

Table 3.

Correlation coefficients (r) between bruise volume, $\mathrm{mm}^{3}$, and firmness, $N$, in several apple and pear varieties; fruits tested the day after harvest. Part of the samples $(n=$ number of fruits) were from the main design, and part from the additional experiments on "Golden Delicious" $(270+440=710)$, and also on "Blanquilla" $(240+240=480)$. All the correlation coeficients were significant at the level of $1 \%$

\begin{tabular}{ccccccc}
\hline & $\begin{array}{c}\text { Golden } \\
\text { Supreme }\end{array}$ & $\begin{array}{c}\text { Golden } \\
\text { Delicious }\end{array}$ & $\begin{array}{c}\text { Granny } \\
\text { Smith }\end{array}$ & Blanquilla & Conference & Guyot \\
\hline$n$ & 270 & 710 & 240 & 480 & 480 & 160 \\
$r$ & -0.20 & -0.26 & -0.26 & -0.41 & -0.33 & -0.45 \\
\hline
\end{tabular}

2. Humidity around the fruit in the last $16 \mathrm{~h}$ before testing affected fruit physical properties and bruise susceptibility. Fruits with high turgidity were more susceptible to bruising.

3. Deformation at skin puncture was shown to be the physical parameter most related to fruit turgidity. This parameter was also related to bruise susceptibility.

4. Fruit at harvest was more susceptible to bruising than fruit after storage. This change can be explained in terms of a decrease in fruit turgidity.

5. Fruits picked early were less susceptible to bruising than those picked later. This can be explained by a decrease in fruit firmness.

6. It was shown that turgidity and firmness influenced bruise susceptibility independently. Their effects combine during fruit ripening.

\section{Acknowledgements}

The funding for this research was obtained from the EC CAMAR Project 8001-CT91-0206 ("Fruit Quality Engineering") and from a Project from the Spanish CICYT numbered AGF92-1255-CE ("Ingeniería de calidad de frutas").

\section{References}

1 Chen P; Sun $Z$ Impact parameters related to bruise injury in apples. ASAE Paper No. 81-3041, 1981

${ }^{2}$ Pang W; Studman C J; Ward G T Bruising damage in apple-to-apple impact. Journal of Agricultural Engineering Research 1992, \$2(4): 229-240

${ }^{3}$ Klein J D Relationship of harvest date, storage conditions, and fruit characteristics to bruise susceptibility of apple. Joumal of American Society of Horticultural Science 1987, 112(1): 113-118

- Johmson D S; Dover C J Factors infuencing the bruise susceptibility of Bramley's Seedling apples. Proceedings of the European Workshop on Impact Damage of Fruits and Vegetables. Zaragoza (Spain) 1990, 87-93

5 Diener $R$ G; Elliot $K$ C; Nesselroad $P$ E; Ingle $M$; Adams R E; Blizzard S H Bruise energy of peaches and apples. Transactions of the ASAE 1979, 22(2): $287-290$

- Brusewitz G H; Bartsch J A Impact parameters related to post harvest bruising of apples. Transactions of the ASAE 1989, 32(3): 953-957

7 Horsfield B C; Fridley R B; Claypool L L Application of theory of elasticity to the design of fruit harvesting and handling equipment for minimum bruising. Transactions of the ASAE $1972,15(4)$ : 746-750 
${ }^{8}$ Siyami S; Brown G K; Burgess G J; Gerrish J B; Tennes B R; Burton C L; Zapp R H Apple impact bruise prediction models. Transactions of the ASAE 1988, 31(4): 1038-1046

Timm E J; Schulte-Pason N L; Brown G K; Burton C L Apple and impact surface effects on bruise size. ASAE Paper No. 89-6048, 1989

To Saltveit $\mathbf{M} \mathbf{E}$ Effects of temperature on firmness and bruising of Starkrimson Delicious and Golden Delicious apples. Horticultural Science 1984, 19(4): 550-551
"Schoor D; Holt $\mathbf{J} \mathbf{E}$ The effects of storage time and temperature on the bruising of Jonathan, Delicious and Granny Smith apples. Journal of Texture Studies 1978. 8: 409-416

${ }^{12}$ García C; Ruiz-Altisent M; Chen P Impact parameters related to bruising in selected fruits. ASAE Paper No. $88-6027,1988$

'3 Strasburger E; Noll F; Schenck H; Schimper A F W; von Denffer D; Bresinsky A; Ehrendorfer F; Ziegler H Botánica (Botany). Barcelona: Maris, 1985. 